\title{
UTILIZACIÓN DE TÉCNICAS DE LÁSER ESCÁNER TERRESTRE EN LA MONITORIZACIÓN DE PROCESOS GEOMORFOLÓGICOS DINÁMICOS: EL MANTO DE NIEVE Y HELEROS EN ÁREAS DE MONTAÑA
}

\author{
J. REVUELTO ${ }^{*}$, J.I. LÓPEZ-MORENO ${ }^{1}$, C. AZORÍN-MOLINA ${ }^{1}$, \\ G. ARGUEDAS ${ }^{2}$, S.M. VICENTE-SERRANO ${ }^{1}$, A. SERRETA ${ }^{3}$ \\ ${ }^{1}$ Instituto Pirenaico de Ecología, Consejo Superior de Investigaciones Científicas (CSIC), \\ Campus de Aula Dei, Avda/ Montañana 1005, 50059 Zaragoza, España. \\ ${ }^{2}$ Escuela Politécnica Superior de Edificación de Barcelona, UPC, \\ Avda/ Doctor Marañón, 44-50, 08028 Barcelona, España. \\ ${ }^{3}$ Escuela Politécnica Superior de Huesca, Universidad de Zaragoza, \\ Carretera de Cuarte, s/n. 22071 Huesca, España.
}

\begin{abstract}
RESUMEN. Este trabajo presenta la aplicación de un láser escáner terrestre de largo alcance para la monitorización de la acumulación de nieve y evolución de heleros en el Pirineo. Con el estudio realizado se muestra el gran potencial de la metodología presentada para estudios en ambientes de montaña, concretamente en investigaciones relacionadas con la monitorización de la criosfera en relación a la variabilidad climática y la topografía compleja propia de ambientes de montaña. Se presenta un protocolo completo para la adquisición y tratamiento de las nubes de puntos medidas por un láser escáner de largo alcance (RIEGL LPM-321) para la generación de modelos digitales del terreno, con el propósito de comparar dichos modelos obtenidos en distintos momentos. Así se obtienen espesores de nieve y cambios de espesor de las masas de hielo. Como casos de estudio se presentan resultados de dos pequeños heleros situados en el macizo de Monte Perdido y la acumulación de nieve en una pequeña cuenca situada en el valle de Tena.
\end{abstract}

Application of terrestrial laser scanner techniques for monitoring dynamic geomorphological processes: snow accumulation and ice masses in mountain areas

ABSTRACT. This paper presents the application of a long range terrestrial laser scanner for monitoring snow accumulation and evolution of glaciers in the Pyrenees. With this study we are showing the great potential of the methodology presented for studies in mountain environments, particularly in research related to the cryosphere monitoring in relation to climate variability and the complex topography typical of mountain environments. We present a comprehensive 
protocol for the acquisition and processing of point clouds measured by a laser scanner (RIEGL LPM-321) for the generation of digital terrain models, in order to compare the models obtained at different times. Thus it is possible to obtain snow thickness and changes of ice thickness. As case studies, results from two small ice masses located in the massif of Monte Perdido and snow accumulation on a small basin located in the Tena Valley are presented.

Palabras clave: láser escáner terrestre, nieve, glaciares, Pirineo.

Key words: terrestrian laser scanner, snow, glacier, Pyrenees.

Enviado el 3 de enero de 2013

Aceptado el 26 de enero de 2013

* Correspondencia: Instituto Pirenaico de Ecología, Consejo Superior de Investigaciones Científicas (CSIC), Campus de Aula Dei, Avda/ Montañana 1005, 50059 Zaragoza. E-mail: jrevuelto@ipe.csic.es

\section{Introducción}

La nieve controla numerosos procesos hidrológicos, geomorfológicos, ecológicos y socioeconómicos en zonas de montaña (Beniston, 2003; López-Moreno et al., 2009). En la montaña española, dicha importancia es particularmente relevante pues la nieve representa la mayor aportación a los caudales de primavera (López-Moreno y García-Ruiz, 2004) y resulta clave para la gestión de los embalses situados en los grandes afluentes que tienen sus cabeceras en zonas de montaña (López-Moreno et al., 2008; LanaRenault et al., 2010 y 2011), por lo que conocer la cantidad de nieve disponible es muy importante para la gestión de los recursos hídricos. Recientemente, la nieve se ha convertido en un importante motor de desarrollo turístico en relación a la práctica de deportes de invierno (Bürki et al., 2003). Por otra parte los pequeños glaciares y heleros pirenaicos resultan elementos del paisaje muy característicos del Pirineo y representan unos indicadores climáticos muy sensibles (Chueca et al., 2005), resultando su retroceso una señal muy perceptible del cambio climático ocurrido en el Pirineo en las últimas décadas (López-Moreno et al., 2006), así como en otras áreas montañosas (Haeberli y Beniston, 1998). A escala global el retroceso de los glaciares y la disminución del manto de nieve en amplias zonas del planeta, representa un reto de cara a la gestión en un futuro cercano para un recurso que afecta a mucha población (Barnett et al., 2005). Por todo ello resulta de interés progresar en el conocimiento de los procesos que controlan la variabilidad espacial y temporal del manto de nieve y de las masas heladas en respuesta a las fluctuaciones y cambios en las condiciones climáticas (López-Moreno y Vicente-Serrano, 2007). Sin embargo, la monitorización de la criosfera resulta muy compleja. En el caso de la nieve por ser un medio extremadamente dinámico en el tiempo, y con una gran variabilidad espacial, incluso a distancias muy cortas (Deems et al., 2006; Fassnacht, 2010). Por otra parte, los heleros y glaciares, al encontrarse en lugares muy alejados y de difícil accesibilidad, resulta muy complejo, y frecuentemente peligroso, 
realizar mediciones sobre el terreno. Por ello es muy común recurrir a distintas técnicas de teledetección (imágenes satélite, LIDAR, radar, etc.) aplicadas en estudios tanto de glaciares como del manto de nieve, que permiten obtener datos con una exposición mucho menor y que aportan información muy valiosa.

En los últimos años, la tecnología LIDAR (Light Detection and Ranging) ha experimentado un gran desarrollo del que ha derivado una generalización en su uso en distintos campos de investigación. Ejemplo de este avance son los láseres escáner terrestres (TLS; Terrestrial Laser Scanner) con tecnología tiempo de vuelo para la adquisición de puntos remotos del terreno, que permiten obtener modelos digitales del terreno (MDT). La posibilidad de adquisición de información tridimensional, la elevada velocidad en la adquisición de puntos, así como la elevada resolución espacial y su precisión han sido claves para un reciente aumento de sus aplicaciones. Así, son numerosos los estudios en el campo de la geomorfología que muestran la utilidad de estas técnicas LIDAR para analizar diversos procesos dinámicos, como muestran recientes trabajos en caídas de bloques (Abellán et al., 2006, 2010), deslizamientos de laderas (Bitelli et al., 2004; Oppikofer et al., 2008; Jaboyedof et al., 2012), dinámica fluvial (Heritage y Hetherington, 2007) o procesos de degradación de suelos (Romanescu et al., 2012) entre otros. Así mismo parte de la versatilidad de los TLS reside en la posibilidad de medición en zonas de montaña de difícil acceso gracias al largo alcance de algunos dispositivos, quedando reflejado en investigaciones de monitorización de glaciares (Avian y Bauer, 2006; Schwalbe et al., 2008) y dinámica del manto de nieve en ambientes de montaña (Grünewald et al., 2010; Egli et al., 2012).

Las ventajas de la tecnología TLS, aplicada a estudios de la criosfera, se hacen más evidentes al compararla con otras técnicas utilizadas para la adquisición de datos. Por ejemplo, la cantidad de datos obtenidos en una campaña de campo con un láser escáner resulta muy superior si se contrasta con técnicas de taquimetría, siendo la precisión de ambas similar (Prockop et al., 2008). De igual forma, numerosos estudios emplean mediciones manuales de espesor de nieve y/o equivalente de agua (SWE; Snow Water Equivalent) distribuidas en el espacio para modelizar estadísticamente la respuesta de la nieve a distintas variables como la vegetación, las características del terreno o la climatología local (Anderton et al., 2004; Pomeroy et al., 2004). Dichos métodos, requieren un gran esfuerzo de trabajo en el campo para la adquisición de una limitada información del manto de nieve; y las estimaciones del manto de nieve que se obtienen de ellas están sujetas a una importante incertidumbre asociada a las propias técnicas de interpolación y la cantidad de datos empleadas en las mismas (Erxleben et al., 2002; Molotch et al., 2005; López-Moreno y Nogués-Bravo, 2006; López-Moreno et al., 2007; López-Moreno et al., 2010). El seguimiento de los glaciares, se basa normalmente en la instalación y seguimiento de un número limitado de estacas de ablación (Singh y Singh, 2001), que requieren un gran esfuerzo de instalación y mantenimiento y, de nuevo, la interpolación de los datos puntuales obtenidos está sujeta a una elevada incertidumbre. Las nubes de puntos tridimensionales obtenidas a partir de escaneos TLS suponen por un lado un gran avance en cuanto al volumen de datos disponibles para trabajos de modelización y una disminución del tiempo de exposición a un ambiente de trabajo complejo y frecuentemente peligroso como lo es la alta montaña. 
Atendiendo a otras técnicas de teledetección aplicadas en estudios del manto de nieve existen diferencias reseñables al compararlas con la tecnología LIDAR. Existe un amplio espectro de satélites que proporcionan productos para la teledetección terrestre como los satélites Terra y Aqua con sensores MODIS (Moderate Resolution Imaging Spectroradiometer), de la misión EOS de la NASA especialmente diseñados para la obtención de datos de la criosfera, o los satélites Landsat y CryoSat-2 de la ESA. Así mismo el abanico de sensores implementados en los satélites es extenso, desde el señalado MODIS, al SAR (Synthetic Aperture Radar) e InSAR (Interferometric Synthetic Aperture Radar), pasando a los sensores térmicos TM (Thematic Mapper) y los sensores de canales visibles e infrarrojo próximo. Diversos grupos de investigación han desarrollado algoritmos para la elaboración de mapas de cobertura de nieve a partir de imágenes de satélite (König y Winther, 2001; Hall et al., 1995). También existen trabajos en los que se estima el SWE a partir de imágenes InSAR (Rott et al., 2004), con limitaciones debidas a la redistribución de la nieve y aplicable únicamente en zonas llanas. Las ventanas espaciales cubiertas por los sensores situados en aviones o satélites no son equiparables a las áreas cubiertas por los TLS, si bien la resolución alcanzada por esta última es notablemente superior al compararla con los $500 \mathrm{~m}$ de resolución que se obtiene de los satélites Terra y Aqua (Parajka y Blöschl, 2008) o los 30 m de los sensores TM de Landsat (Guneriussen et al., 2001). Otro inconveniente de la utilización de teledetección a larga distancia es la necesidad de corrección de la reflectancia en cada pixel; debido a efectos de sombras originados por el terreno, así cómo la diferenciación de tipos de terreno en un mismo pixel (Rosenthal y Dozzier, 1996). También la cobertura nubosa representa un problema para la observación del terreno por lo que es necesario aplicar técnicas de filtrado que permiten eliminar gran parte de la nubosidad (Parajka y Blöschl, 2008), pero no la totalidad. Debido al reducido tamaño de los glaciares pirenaicos, las técnicas de teledetección desde satélites resultan limitadas, si bien se han realizado estimaciones de la cubierta glaciar del Pirineo aragonés utilizando imágenes Landsat (Cano y Recio, 2004). El método más utilizado para el análisis de la evolución de la superficie glaciar ha sido la comparación de cartografías derivadas de fotografías aéreas y ortofotos (Chueca et al., 2005). Además, la comparación de mapas topográficos ha permitido estimar pérdidas de grosor de hielo en el glaciar de la Maladeta (Chueca et al., 2007). Las ventajas que brinda el TLS en cuanto a resolución y posibilidad de obtención de espesor del manto de nieve y pérdidas de volumen de glaciares en zonas de montaña hacen que, para áreas reducidas, represente una nueva fuente de información muy potente comparada con otras técnicas de teledetección.

Además, existen otra técnicas de teledetección sobre el terreno como el la tecnología de radar terrestre (GPR, Ground Penetrating Radar) que se ha aplicado para la monitorización del espesor de glaciares en el Pirineo con GPR (del Río et al., 2012) o en otras zonas para determinar el espesor y la densidad del manto de nieve, presentando problemas cuando la nieve contiene una porción importante de agua en estado líquido (Andersen et al., 1987). Igualmente radares GBSAR (Ground Based interferometric Synthetic Aperture Radar) permiten obtener mediciones directas del espesor del manto de nieve, si bien para calcular el SWE necesitan ser complementadas con otras técnicas como el TLS para obtener las condiciones iniciales del manto de nieve (Schaffhauser et al., 2008). Los 
datos generados por los TLS tienen mejor resolución espacial además de ser equipos más manejables en campo, por lo que su uso está más generalizado que el de los GBSAR.

Sin embargo, los TLS también presentan una serie de inconvenientes que deben ser considerados para su aplicación en estudios de la criosfera. Ejemplo de ello son los tiempos de medición, notablemente superiores a la tecnología GBSAR, la dificultad de adquisición de puntos bajo condiciones meteorológicas adversas (precipitación intensa, nubosidad, etc.), la estabilidad del sistema o el cambio en las condiciones del manto de nieve (Prockop, 2008). No obstante si se minimizan en la medida de lo posible estos problemas, aplicando rigurosamente la metodología de trabajo seguida en el presente estudio, los láser escáner terrestres de larga distancia son la tecnología con mejores resultados de medición directa del espesor de nieve y hielo para distancias de alrededor de $500 \mathrm{~m}$ (Lundberg et al., 2008) e incluso superiores a $2000 \mathrm{~m}$ con una error en la medición de espesor inferior a $20 \mathrm{~cm}$ en condiciones óptimas de trabajo (Prockop, 2009).

El trabajo que se presenta describe la metodología empleada para la monitorización con un TLS de largo alcance (LPM-321 de RIEGL) en una cuenca de alta montaña del Pirineo Central para el estudio del manto de nieve y la evolución del hielo de dos heleros, pudiendo servir de ejemplo para su aplicación en zonas de alta montaña.

\section{Zonas de estudio}

Entre 2000 y $2300 \mathrm{~m}$ sobre el nivel del mar se encuentra una pequeña cuenca hidrológica de pasto subalpino, que desde hace mas de 25 años viene siendo una zona de estudio del Instituto Pirenaico de Ecología para investigaciones hidrológicas y climáticas. Con una extensión aproximada de 33 ha, resulta de un elevado interés cuantificar las diferencias de acumulación de la nieve condicionadas por múltiples factores como la curvatura del terreno, la pendiente o la exposición a la radiación solar así como relacionarlo con la meteorología y la climatología local.

En la zona más septentrional del Parque Nacional de Ordesa y Monte Perdido se encuentra el conocido como Balcón de Pineta, un valle Glaciar suspendido por encima de los 2600 m sobre el nivel del mar. Situados al sur del Balcón, se localizan dos picos que superan los $3300 \mathrm{~m}$ de altitud (Monte Perdido y Cilindro de Marboré) con uno de los mayores glaciares que actualmente se conservan en el Pirineo, el Glaciar de Monte Perdido. Bajo las paredes rocosas en las que descansa el glaciar se sitúan dos heleros de unas 2.6 ha y 6 ha respectivamente, que vienen sufriendo un fuerte deterioro en los últimos años. La localización geográfica de ambas zonas puede observarse en la Fig. 1.

\section{Metodología}

Actualmente existen numerosos modelos de laser escáner con un amplio espectro de tecnologías de trabajo para distintas aplicaciones, diferenciándose a efectos prácticos por su velocidad de muestreo, distancia de medición y por la longitud de onda con la que trabajan (Ingensand, 2006). En la presente investigación se ha utilizado el modelo LPM- 


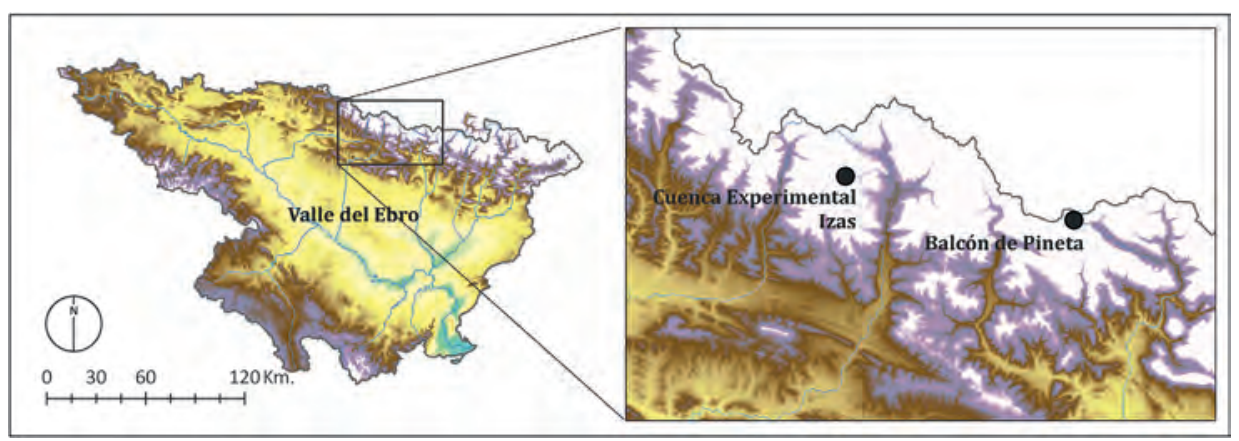

Figura 1. Localización de las zonas de estudio.

321 de RIEGL que emplea la tecnología de tiempo de vuelo (Fig. 2) para determinar la distancia de los distintos puntos de la zona de escaneo y obtener la nube de puntos tridimensional del área deseada. Las especificaciones técnicas de este modelo son las óptimas para el propósito con el que sea empleado: la distancia máxima a la que puede trabajar es de 6 kilómetros, con una resolución angular límite de $0.018^{\circ}$ y frecuencias de muestreo entre 10 y $1000 \mathrm{~Hz}$. Además, la longitud de onda en la que trabaja es $905 \mathrm{~nm}$, y resulta ideal para no ser absorbida por la superficie del hielo o la nieve (Prockop, 2008), habiéndose detectado problemas de pérdida de señal únicamente por un elevado ángulo de incidencia entre el haz de luz láser emitida por el dispositivo y la superficie escaneada en distancias superiores a $1500 \mathrm{~m}$ o por condiciones meteorológicas adversas. Al emplear una técnica en su fase inicial de aplicación para el estudio de la cobertura nivosa y de hielo, es importante establecer una serie de pasos que ayuden a minimizar cualquier fuente de error y a su vez aseguren una buena calidad en los datos (Reshetyuk, 2006; Prockop, 2008).

\subsection{Adquisición de datos con Láser Escáner Terrestre de largo alcance}

El trabajo con un equipo de largo alcance tiene grandes ventajas. Sin embargo, al trabajar en distancias que pueden superar los $1000 \mathrm{~m}$, cabe la posibilidad de que diversas consideraciones técnicas o pequeños errores operativos no considerados en su debido momento, den lugar a grandes desviaciones de las mediciones reales; por ello se establece el siguiente protocolo de operación.

\section{a) Posicionamiento del escáner}

En una fase inicial es importante establecer la localización, o localizaciones, óptimas donde montar el equipo (posición de escaneo). Desde ella, se definen las ventanas angulares para las que se realizan los distintos escaneos. En esta elección debe tenerse en cuenta la existencia de sombras que pueden originar elementos naturales, como un árbol o una colina, situada entre el TLS y el área sometida a estudio (Fig. 3). Para minimizar las zonas de sombra en la superficie de interés, se recomienda realizar diversos 


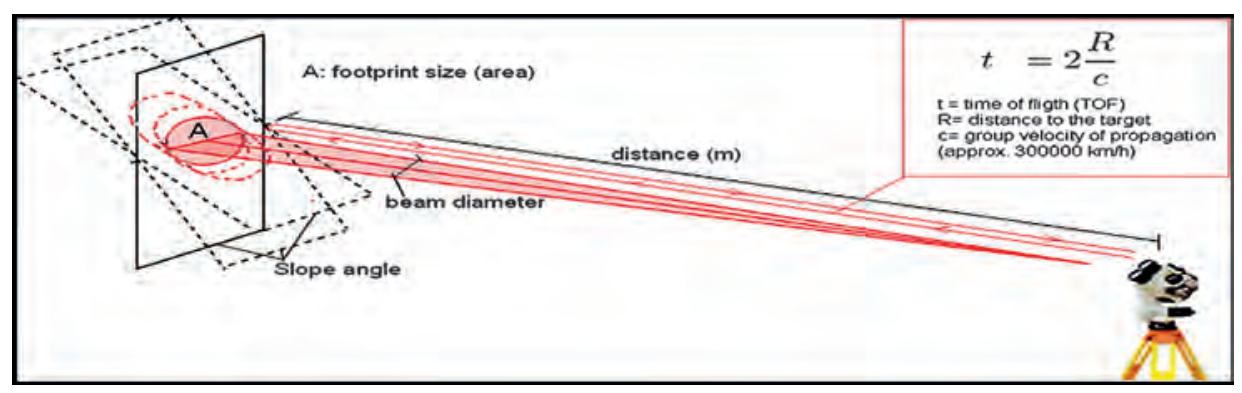

Figura 2. Tecnología tiempo de vuelo (Fuente: Prockop 2008).

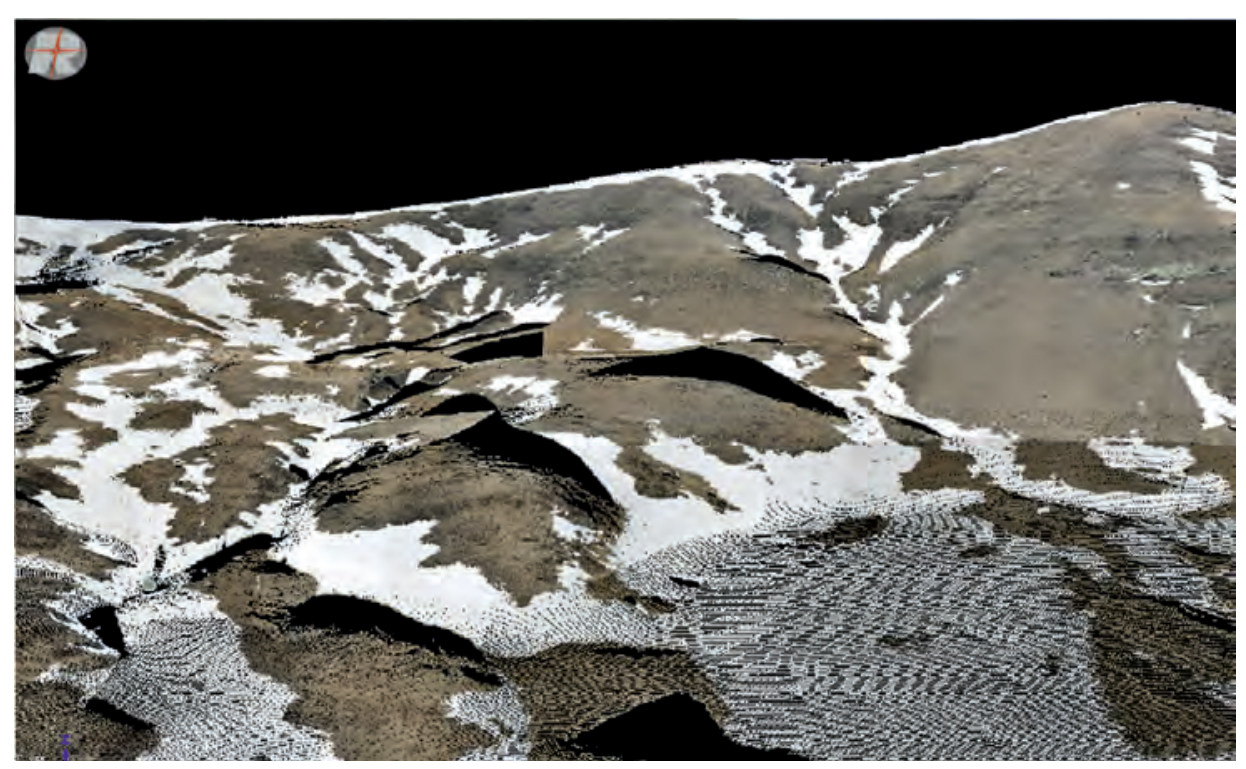

Figura 3. Nube de puntos con colores del canal visible donde se observan sombras originadas por la topografía (Cuenca experimental de Izas).

escaneos desde posiciones distintas, permitiendo escanear el mismo elemento desde dos perspectivas angulares distintas y complementarias. Una vez establecida esta posición se empleará sistemáticamente de modo que los datos de distintas campañas tengan áreas de estudio similares.

El trípode sobre el que se asienta el TLS debe estar bien asentado sobre el terreno y una vez se ha fijado la posición de todo el montaje es extremadamente importante evitar cualquier pequeño movimiento o vibración del TLS que podría causar importantes errores de medición. El TLS se acopla al trípode topográfico mediante una base nivelante, la cual debe ser de una elevada calidad para soportar y fijar de manera óptima el 
dispositivo. Otros autores, coincidiendo con nuestra experiencia, inciden en la importancia de la estabilidad del conjunto señalado (Scaioni, 2005).

\section{b) Registro de la posición del escáner}

El TLS es un dispositivo que adquiere las coordenadas de puntos en un sistema de referencia propio con origen en el interior del instrumento (SOCS, System Own Coordinate System). Cada posición de escaneo tiene su propio SOCS, por lo que todos escaneos obtenidos en una misma posición se solapan directamente. Sin embargo, para solapar escaneos obtenidos desde distintas posiciones de escaneo es necesario conocer la transformación entre los SOCS de cada una y establecer el denominado PRCS (Proyect Coordinate System) de cada día de muestreo. En la comparación final de nubes de puntos y obtención de los MDT, es necesario conocer la transformación entre las distintas campañas cada una en su propio PRCS y un sistema de coordenadas global GLCS (Global Coordinate System). Las señaladas transformaciones entre los sistemas de coordenadas deben hacerse en base a unos puntos fijos con coordenadas conocidas que deben ser adquiridos por el escáner. Este proceso de adquisición de puntos fijos conocidos se le denomina registro de la posición del escáner y se realiza cada vez que el TLS es ensamblado en una posición de escaneo. El registro de la posición del escáner se repite cada hora y media de trabajo, debido a variaciones ambientales y consideraciones de estabilidad que se señalarán más adelante.

Existen dos tipos de registro, directo e indirecto (Reshetyuk, 2006). En el primero de ellos el escáner se posiciona sobre un punto de coordenadas conocidas, centrado, nivelado y con una altura entre el punto y el origen del TLS conocida. Para determinar la orientación de los ejes es necesario emplear un segundo punto de referencia del que también se conocen las coordenadas y que tras ser escaneado, permite en la fase de postproceso realizar la transformación de coordenadas. Esta metodología transforma directamente las coordenadas locales de la nube de puntos en coordenadas globales. El segundo tipo de registro, el indirecto, emplea al menos tres puntos comunes para las distintas posiciones de escaneo de cada área de estudio que permanecen fijas en todo momento (en dichos puntos se fijan unos reflectores). Una vez escaneados estos puntos de unión, es posible establecer en la fase de post-proceso un sistema de referencia para cada zona de interés (PRCS) y en última instancia transformarlas a coordenadas globales (GLCS) al adquirir sus posiciones con métodos de posicionamiento topográficos. En la Fig. 4 se observa la posición de los puntos de unión, así como las posiciones de escaneo desde las que se han adquirido los datos en la cuenca experimental de Izas.

Los resultados mostrados bajo estas líneas han sido obtenidos mediante un registro indirecto de las posiciones de escaneos. Los reflectores posicionados como puntos de unión pueden tener distintas características (forma y tamaño), en función de los requerimientos de distancia y posicionamiento. Para las distancias en que se ha trabajado se emplean dos tipos de cilindros de 10 y $25 \mathrm{~cm}$ (tanto diámetro como altura). Para aumentar el grado de confianza, se ha empleado un mínimo de nueve puntos de unión, duplicando la adquisición de posición de cada uno de ellos en cada posición de escaneo. Debido al movimiento inherente a la operatividad del TLS se produce una vibración en 


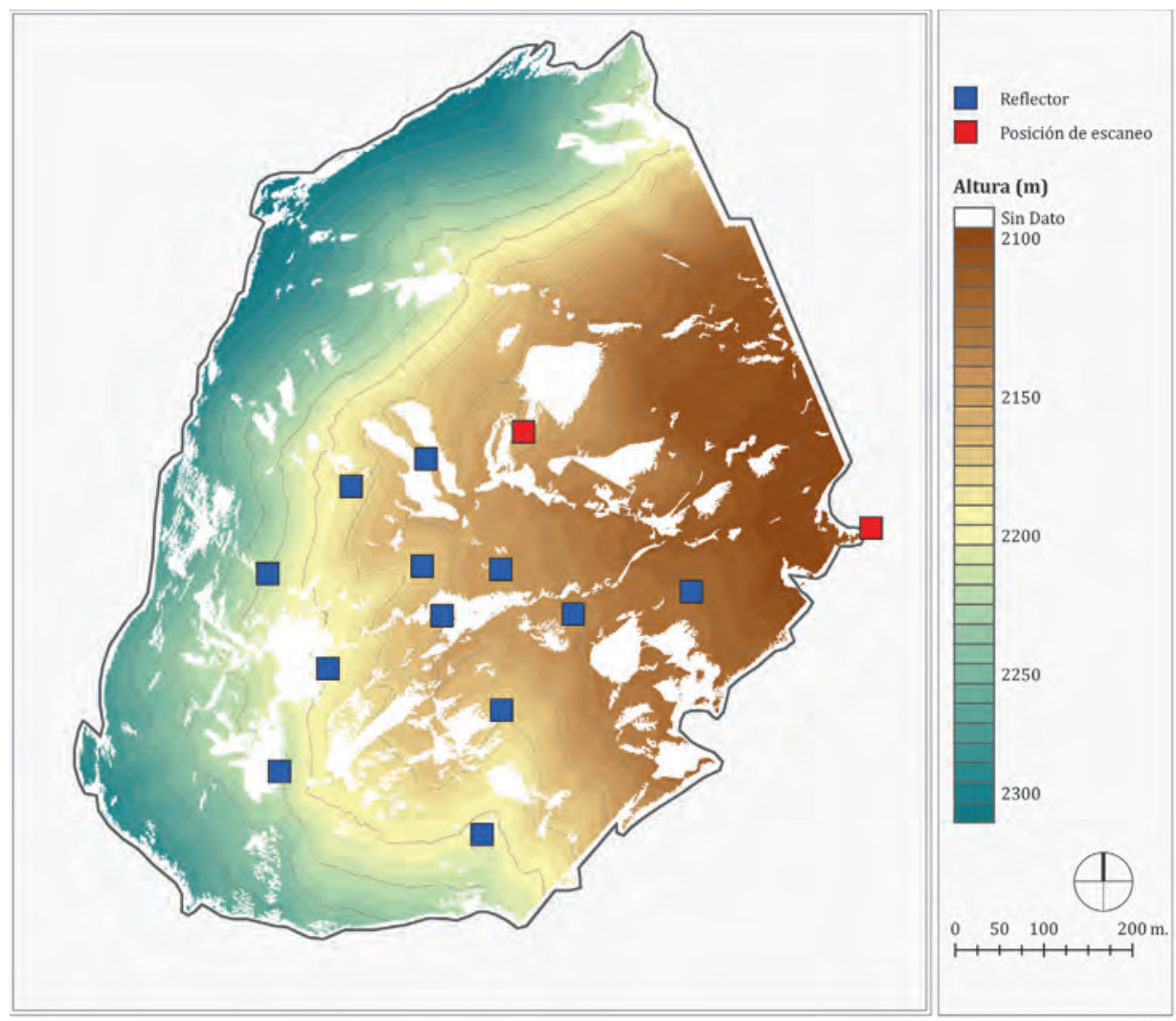

Figura 4. MDT de la cuenca experimental de Izas con la situación de las posiciones de escaneo y los puntos de unión.

todo el sistema que puede originar, y de hecho así ha ocurrido en alguno de los escaneos realizados, inestabilidad del dispositivo. Esto se traduce en una desviación de los datos recogidos haciendo inservible la medición. En la mayoría de los casos esto queda solucionado al respetar el límite de una hora y media de escaneo, tomando de nuevo la posición de los reflectores antes de continuar.

Previamente a la adquisición de la nube de puntos, se debe realizar una corrección atmosférica, pues los pulsos de luz láser emitidos por el TLS viajan a través de un medio que es el aire y su velocidad de propagación depende de la temperatura, humedad y presión de este medio. Errores de $5^{\circ} \mathrm{C}$ en la temperatura, o de $20 \mathrm{mb}$ de presión dan lugar a cambios en la distancia adquirida por el TLS de $5 \mathrm{~mm}$ para distancias de $100 \mathrm{~m}$ (RIEGL, Users guide). De nuevo, resulta importante repetir la corrección cada hora y media de trabajo como máximo, evitando así variaciones atmosféricas que influyen en la medida. Así mismo, se evitan cambios sustanciales en la superficie de la nieve, como el tipo de grano o el contenido de agua líquida, que afectan a la señal reflejada. 


\section{c) Escaneado de la zona de interés y adquisición de imágenes}

Según la distancia a la que se pretende escanear y la resolución espacial de la malla a obtener, se selecciona el modo de trabajo del TLS, que controla la frecuencia e intensidad de la señal emitida. La resolución angular mínima es de $0.018^{\circ}$ lo que se traduce en una separación de aproximadamente $15 \mathrm{~mm}$ entre puntos consecutivos a $50 \mathrm{~m}$ de distancia. Es conveniente resaltar la importancia de encontrar un compromiso entre la resolución, la frecuencia de muestreo y el área a escanear pues de ellos dependerá el tiempo de escaneo. También en este punto hay que señalar la importancia de que los distintos escaneos solapen correctamente, de lo contrario es posible perder información de las zonas de estudio.

Puesto que el TLS emite pulsos de luz láser, cuando las condiciones meteorológicas son adversas, la señal puede ser o bien absorbida (niebla) o reflejada erróneamente por lluvia o nieve intensa, dando como resultado mediciones erróneas de puntos. Así mismo el viento intenso puede influir en la estabilidad del TLS acoplado al trípode topográfico. Por ello se hace obligatorio descartar dichas condiciones durante el periodo de adquisición de datos.

El receptor de la señal láser reflejada por la topografía, también presenta problemas cuando trabaja a largas distancias (superiores a $1500 \mathrm{~m}$ ) y sobre la zona que se está escaneando incide directamente luz solar o la misma alcanza el TLS. El espectro de emisión del sol incluye la longitud de onda a la que trabaja el dispositivo por lo que si la señal reflejada no tiene suficiente intensidad no se detecta y el punto no es registrado. Para zonas en las que ocurre este efecto es conveniente escanear a últimas o primeras horas del día e incluso de noche, pudiendo adquirir estos puntos no detectados previamente, ya sea por saturación del detector y/o el ratio señal-ruido (Wehr y Lohr 1999). Otro factor que afecta a la intensidad de la señal reflejada es el ángulo de incidencia del haz de luz y la normal de la superficie en función de la reflectividad del terreno (Wagner et al., 2004). Este efecto se ve potenciado al combinarse con la luz solar, habiéndose observado, a distancias superiores a $1500 \mathrm{~m}$, problemas de retorno de señal con superficies de nieve con elevado contenido en agua, para ángulos superiores a $35^{\circ}$. En último término la divergencia del haz de luz láser inherente a la óptica del sistema $(0.8 \mathrm{~m} \mathrm{rad})$, hace que las medidas puntuales lo sean en realidad de un área elíptica determinada; footprint o huella (Fig. 2). Existe un solapamiento máximo entre huellas contiguas (Lichte y Jamtsho, 2006), que las propias especificaciones técnicas del LPM321 respetan. Así, para una distancia de $200 \mathrm{~m}$ y un ángulo de incidencia de $0^{\circ}$, el área del footprint es de $0.02 \mathrm{~m}^{2}$, pasando a $0.11 \mathrm{~m}^{2}$ para $80^{\circ}$; aumentando las mismas a $0.5 \mathrm{~m}^{2}$ y $2.9 \mathrm{~m}^{2}$ respectivamente para distancias de $1000 \mathrm{~m}$ (Prockop, 2009). El tamaño de la huella, hace que a grandes distancias, por encima de $2000 \mathrm{~m}$, la exactitud de la medición decrezca, pues para distancias de $4000 \mathrm{~m}$ y ángulos de incidencia normales $\left(0^{\circ}\right)$, el área será superior a $8 \mathrm{~m}^{2}$, llegando a $46 \mathrm{~m}^{2}$ con ángulos de $80^{\circ}$.

Numerosos modelos de TLS disponen de una cámara fotográfica calibrada, que está acoplada al láser escáner, permitiendo la adquisición de imágenes de la zona escaneada, lo que proporciona información RGB (RedGreenBlue, información de color verdadero de cada píxel) para cada punto (Fig. 3). Dicha información resulta de interés para validar las mediciones (discriminación entre áreas cubiertas y libres de nieve). Por ello tras escanear las zonas de interés con las consideraciones señaladas, se adquieren fotos del área escaneada. 
La estabilidad del terreno combinada con la propia vibración del TLS mientras trabaja, ya señalada en el apartado anterior, puede originar pequeñas desviaciones de unos segundos de arco, que a grandes distancias llevan a errores en distancia de algunos metros. Para acotar la desviación, se establece como límite $20 \mathrm{~cm}$ de error en las coordenadas (X, Y, Z en SOCS) del centro de un mismo punto de unión situado a $600 \mathrm{~m}$ del TLS para considerar estable una campaña de muestreo (Prockop, 2008). Así mismo, este criterio se emplea en el denominado test de reproducibilidad, definido como la proximidad en las coordenadas de un mismo objeto fijo (rocas, árboles...), común entre dos nubes de puntos adquiridas en distinto momento. Este test se debe aplicar sistemáticamente en todas campañas, descartando aquellos escaneos que no lo cumplen.

La frecuencia temporal con la que se han realizado las campañas de muestreo depende de los intereses en cada zona de estudio. Así, para la medición del manto de nieve se realizan numerosos escaneos a lo largo del año, con una frecuencia mensual durante los meses de acumulación (diciembre, enero, febrero y marzo), pasando a quincenal durante el periodo de fusión (abril, mayo). En el caso de los heleros se realizan mediciones anuales pues el objetivo es monitorizar la evolución interanual de los mismos.

\subsection{Georreferenciación de la nube de puntos}

Para poder relacionar la información adquirida mediante TLS con otras fuentes de información (por ejemplo otras capas de cartografía digital o imágenes de satélite), resulta necesario convertir las coordenadas relativas del proyecto PRCS a un sistema de coordenadas absoluto GLCS. Para ello deben obtenerse las coordenadas precisas de los reflectores. Este paso resulta crucial, ya que pueden introducirse desplazamientos considerables entre nubes de puntos de una misma zona. Las coordenadas aquí obtenidas son las empleadas en el post-proceso para la transformación de coordenadas a un sistema global de coordenadas.

En el caso de Izas, para la georreferenciación de los puntos de control (puntos de unión) se combinaron técnicas de posicionamiento GPS diferencial en post-proceso con topografía clásica (estación total). En primer lugar hay que materializar una red de dos bases de manera que en una de ellas se tenga una visión total de todos los reflectores instalados en la zona de interés. Estas dos bases conformarían una red de tres bases junto a la Estación de Rastreo Permanente del SITAR (Sistema de Información Territorial de Aragón) de Sabiñánigo, que es la más cercana a la cuenca. La red presenta dos vectores largos de $30 \mathrm{~km}$ aproximadamente y un vector muy corto, de en torno a $100 \mathrm{~m}$, formado por las dos bases escogidas y materializadas sobre el terreno. Las observaciones de GPS estáticas tuvieron una duración de dos horas para los vectores largos, y de media hora para el vector corto. Tras el post-procesado y el ajuste de la red tomando un punto de control cuyas coordenadas eran conocidas, el de la estación permanente de Sabiñánigo, se obtienen coordenadas geográficas en sistema de referencia WGS84 con una precisión de unos $5 \mathrm{~cm}$ en planimetría y unos $10 \mathrm{~cm}$ en altimetría. Conocida la posición espacial de las bases, es posible realizar una radiación con la estación total, a todos los reflectores y calcular sus coordenadas, empleando para orientar las lecturas en la segunda base cuyas coordenadas también son conocidas. En la cuenca experimental de Izas, 


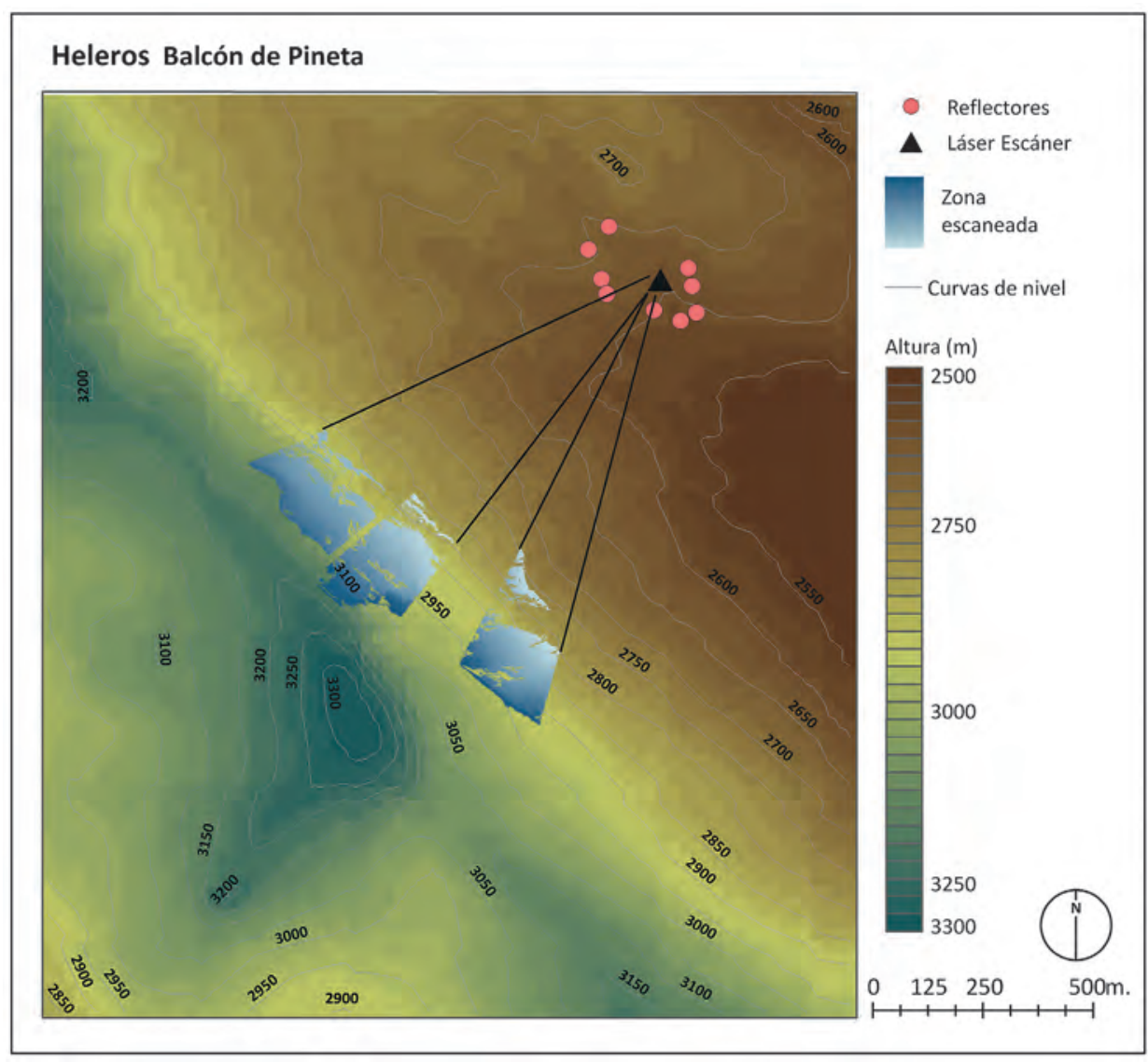

Figura 5. Zonas escaneadas en el Balcón de Pineta y situación de Reflectores (puntos de unión) y Láser Escáner (posición de escaneo).

las mediciones mediante estación total conllevan un error transversal de $4.2 \mathrm{~cm}$, así como un error longitudinal de $0.32 \mathrm{~cm}$.

Las coordenadas de los reflectores empleados en la zona del balcón de Pineta (ver Fig. 5 con el MDT de la zona y la posición de los reflectores), se obtuvieron directamente con posicionamiento GPS. El primer año en que se realizó la medición del glaciar se estableció una base con un tiempo de observación superior a las cuatro horas que tras el post-proceso con las bases del SITAR de Sabiñánigo, Bielsa y Graus permitió obtener las coordenadas con una precisión de $1.14 \mathrm{~cm}$. En la última campaña, empleando la citada base del año anterior, se adquirieron las coordenadas de los reflectores mediante RTK (navegación cinética satelital en tiempo real) con un segundo GPS comunicándose con el de la base. En este caso las coordenadas de cada reflector se tomaron con una precisión ligeramente inferior a $2 \mathrm{~cm}$ en coordenadas geográficas WGS84. 


\subsection{Post-proceso y generación de mapas de espesor}

Los escaneos obtenidos en cada campaña desde distintas posiciones deben solaparse, calculando una matriz de traslación y rotación a partir de las posiciones de los puntos de unión comunes adquiridas en cada posición de escaneo durante el registro. Por último se realiza la transformación a coordenadas UTM de la nube de puntos en base a las coordenadas adquiridas (según lo descrito en el apartado 3.2). Este proceso de transformación entre sistemas de coordenadas tiene como indicador de calidad la desviación estándar en el solapamiento entre los reflectores de una zona de escaneo, que permite evaluar la calidad de los datos. Así, Prockop (2008), en un trabajo de validación de medición de espesores de nieve con tecnología TLS, obtenía unas desviaciones estándar de $0.002 \mathrm{~m}$ con otros modelos de escáner. Una vez los datos se encuentran en un sistema de coordenadas globales, se filtran los datos eliminando puntos no deseados, como la vegetación, o zonas fuera del área de interés. Puesto que en muchos casos la información adquirida mediante el TLS puede ser redundante, también se realiza un filtrado de puntos, permitiendo así una reducción en el volumen de datos. Los pasos hasta aquí señalados se realizaron con el software Riprofile, especialmente desarrollado para operar el TLS y trabajar las nubes de puntos tridimensionales que genera.

Dependiendo de cómo se pretende afrontar el tratamiento de las nubes de puntos y la generación del MDT, es posible crear superficies mediante triangulación de los puntos en tres dimensiones (opción que presentan diversos software, como Riprofile) o bien rasterizar los datos y trabajar con Sistemas de Información Geográfica (SIG). Dada la mayor versatilidad en cuanto a tratamiento de información geográfica, exportación e importación a diversos software y la posibilidad de complementar con otras fuentes (imágenes de satélite, fotos aéreas...), en este estudio se ha trabajado con imágenes raster generadas con el software MiraMon v. 6.4. Tras exportar los ficheros de puntos de cada campaña en coordenadas UTM, son importados como un fichero de puntos vectorial, que es posteriormente rasterizado. Así, se generan modelos digitales del terreno de las cuenca de Izas cubierta de nieve, y otra capa de referencia a partir del escaneo realizado una vez que toda la nieve ha desaparecido. Sustrayendo el MDT de referencia a los MDTs obtenidos durante el periodo con innivación, se obtienen directamente los espesores de nieve. En el caso de los heleros de Marboré, cada escaneo proporciona un MDT anual, cuya diferencia informa de los cambios en espesor de hielo de un año para otro. Para eliminar zonas con ausencia de datos entre los MDT comparados, se crean máscaras con las zonas de sombras en cada campaña y se consideran únicamente aquellas zonas en que exista dato en ambos ráster. Estas diferencias en las sombras son originadas por las distintas acumulaciones de nieve a lo largo de la temporada.

\section{Aplicación y resultados en las zonas de estudio}

\subsection{Cuenca experimental de Izas}

Se escaneó la cuenca de Izas a una resolución espacial variable (según distancias y condiciones atmosféricas), pero siempre inferior a $50 \mathrm{~cm}$ (zonas mas alejadas del escáner a unos $950 \mathrm{~m}$ de éste). En esta zona se establecieron dos posiciones de escaneo (Fig. 4) separadas entre sí $450 \mathrm{~m}$ con el propósito de reducir las sombras topográficas en los 


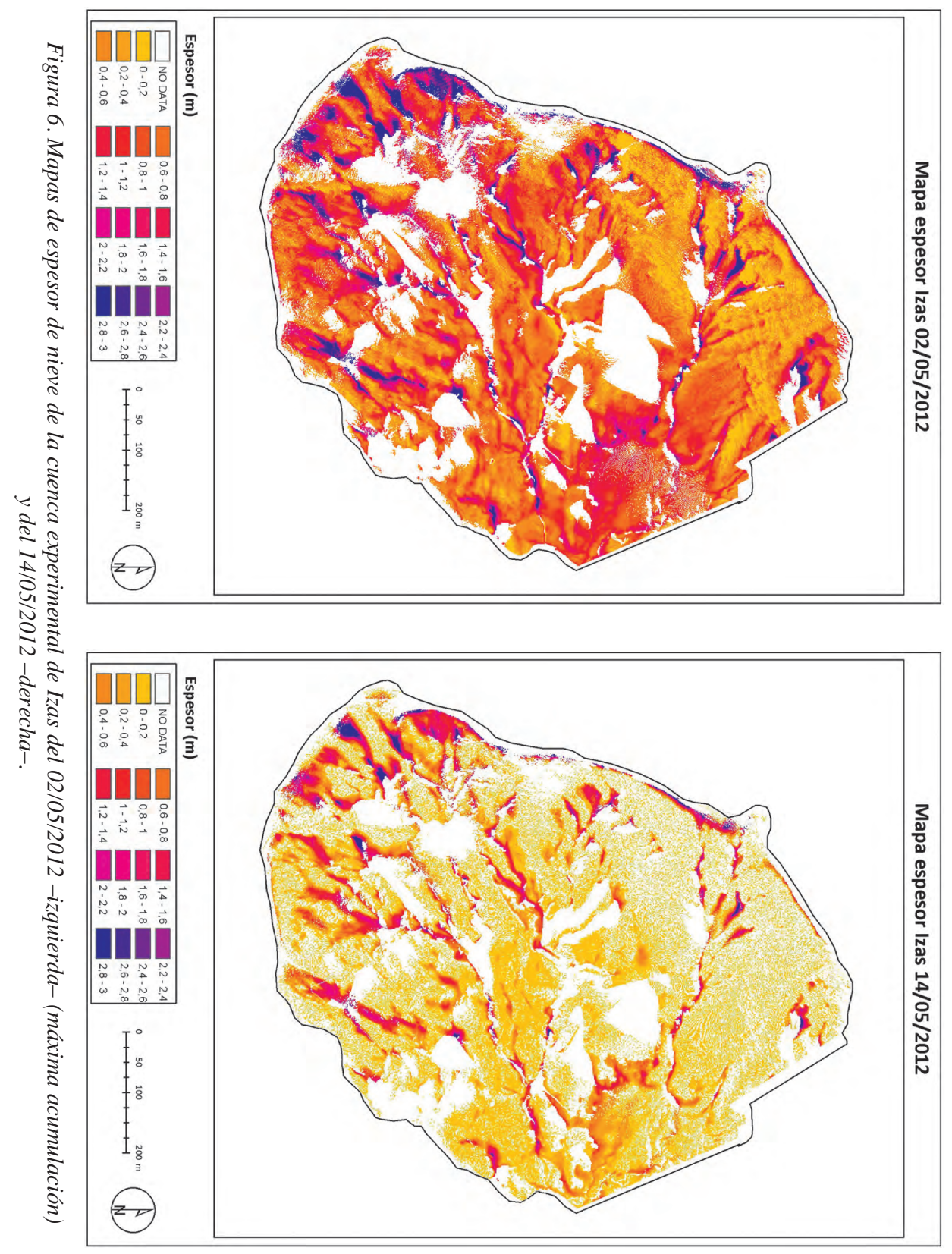


escaneos. Para disminuir el ruido en los datos finales se ha empleado un tamaño de celda para los MDT de 1x1 m. La resolución temporal es aproximadamente mensual, incrementándose a quincenal durante el periodo de fusión, habiéndose realizado un total de seis campañas a lo largo del invierno 2011-2012. El MDT de referencia para el cálculo de los espesores se obtuvo mediante un escaneo realizado en Julio de 2012. Para las distancias en las que se ha trabajado, la desviación estándar del solape de las nubes de puntos, en las coordenadas de los puntos de unión se ha movido en unos valores entre $0.0247 \mathrm{~m}$ y $0.0084 \mathrm{~m}$ para la cuenca experimental de Izas (reflectores situados entre $110 \mathrm{~m}$ y $730 \mathrm{~m}$ de las posiciones de escaneo).

En la Fig. 6 se muestran los mapas de espesor, correspondientes al día de máxima acumulación de la pasada temporada (02/05/2012) y una campaña realizada unos días después tras unas condiciones meteorológicas favorables a la fusión del manto (14/05/2012). En el mapa de la izquierda de la Fig. 6 se observan zonas de máxima acumulación, correspondientes a zonas cóncavas de la topografía (barrancos y pequeños cursos de agua), en las que se mantienen espesores de nieve considerables tras el periodo de fusión (mapa parte derecha Fig. 6), mientras en otras zonas de la cuenca la nieve se ha fundido por completo (colores amarillos claros).

La Fig. 7 muestra la distribución de la superficie de nieve, apreciándose claramente las áreas con y sin cubierta de nieve obtenida a partir de las fotografías. Debe notarse que al comparar los mapas de espesores y los de color RGB, se pueden evaluar los datos obtenidos y hacer una primera estimación de la calidad de los datos en lo que a superficie cubierta por nieve se refiere. Si se compara el mapa de la Fig. 6 del día 14/05/2012 con el mapa de la Fig. 7, se puede apreciar que el límite de nieve queda bien representado, habiéndose detectado pequeños errores en zonas limítrofes en las que el espesor es inferior a $10 \mathrm{~cm}$, de donde se deduce que las fotos son una buena herramienta para evaluar los datos obtenidos.

En vista a estos resultados queda clara la capacidad de la metodología presentada para obtener mapas de espesor de nieve a una resolución espacial baja y un error de medición en el espesor de nieve inferior a $20 \mathrm{~cm}$ para distancias de hasta $1000 \mathrm{~m}$ corroborando así los resultados de estudios previos (Prockop, 2009).

\subsection{Heleros del Balcón de Pineta}

Se obtuvieron dos MDTs en el otoño de 2011 y 2012. Ambas tomas de datos se realizaron en el momento de mínima acumulación una vez concluido el verano (25/09/2011 y 20/09/2012), habiéndose encontrado pérdidas significativas de espesor en algunas zonas de los heleros (Fig. 8). Las distancias entre las zonas escaneadas y la posición de escaneo quedan comprendidas entre 850 y 1000 m; la resolución espacial mas baja entre puntos adquiridos por el escáner es de $0.4 \mathrm{~m}$, y el tamaño de celda de los MDT generados es de $1 \mathrm{~m}$. Conviene señalar que los puntos de unión de estas campañas no quedaron fijos sobre el terreno y se posicionaron para cada una de las mismas, adquiriendo las coordenadas UTM de los mismos por los mencionados méto- 
Figura 7. Composición $R G B$ en un ráster a partir de las imágenes adquiridas con la cámara fotográfica acoplada al TLS para el día 14/05/2012.

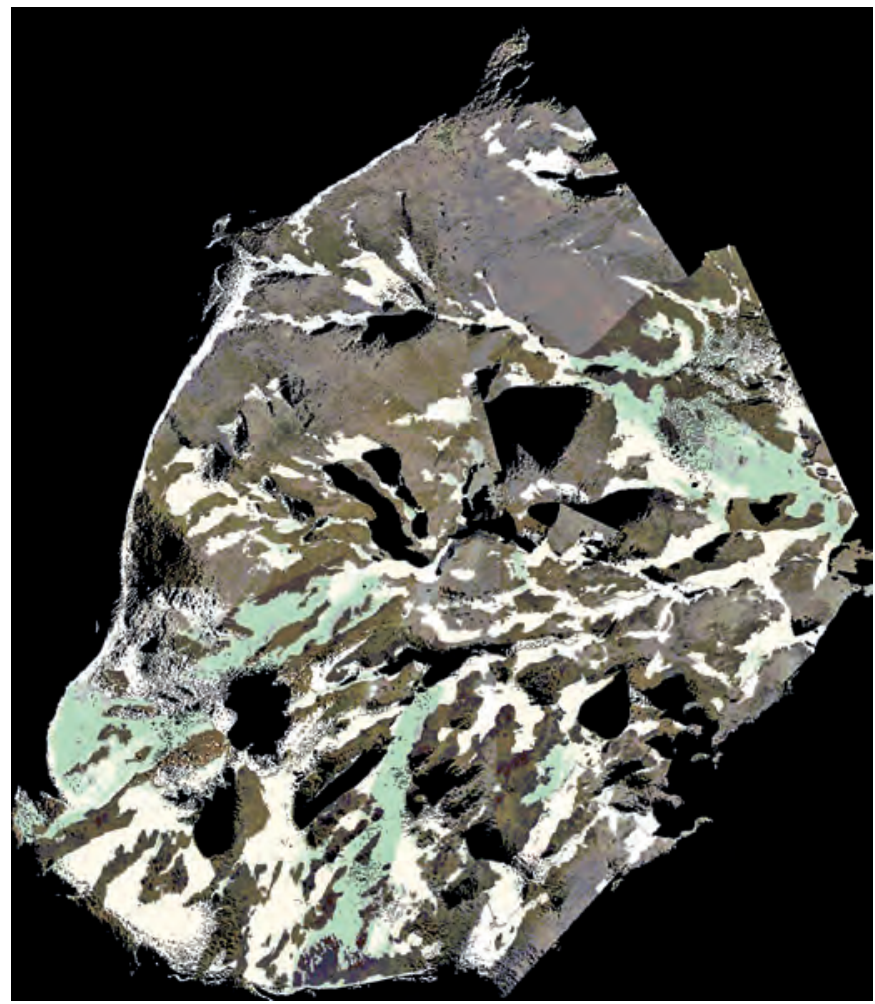

dos de topografía (sección 3.2). Además, se han utilizado elementos característicos del terreno (rocas, grietas, etc.) como puntos comunes para mejorar el solape de distintos escaneos.

La Fig. 8 presenta los mapas de pérdidas de espesor en ambos heleros. El descenso durante el primer año de monitorización en la mayor parte de los heleros oscila, en general, entre 0.5 y $4 \mathrm{~m}$, llegando en algunas zonas puntuales a perderse hasta $5.5 \mathrm{~m}$. Las zonas en las que se observa una mayor disminución se encuentran situadas en la parte inferior de los heleros disminuyendo el valor de las pérdidas conforme nos acercamos a las zonas mas elevadas, lo cual es consecuente con la dinámica de estas masas de hielo (López-Moreno et al., 2006). Asimismo, en el mapa situado a la derecha de la Fig. 8, es posible observar una zona en el margen inferior derecho con una pérdida de espesor uniforme y de pequeño valor comparado con las pérdidas constatadas en otras zonas. Esta área corresponde a un canchal de rocas que cubre el hielo y lo protege de la radiación, lo que causa una menor pérdida de hielo que en las zonas de hielo descubierto. La elevada pérdida de hielo se explica por las condiciones climáticas tan extremas observadas entre los dos periodos de medición. La precipitación en forma de nieve ha sido escasa y las temperaturas de verano muy superiores a la media histórica, lo que explica un balance de masa claramente negativo. 


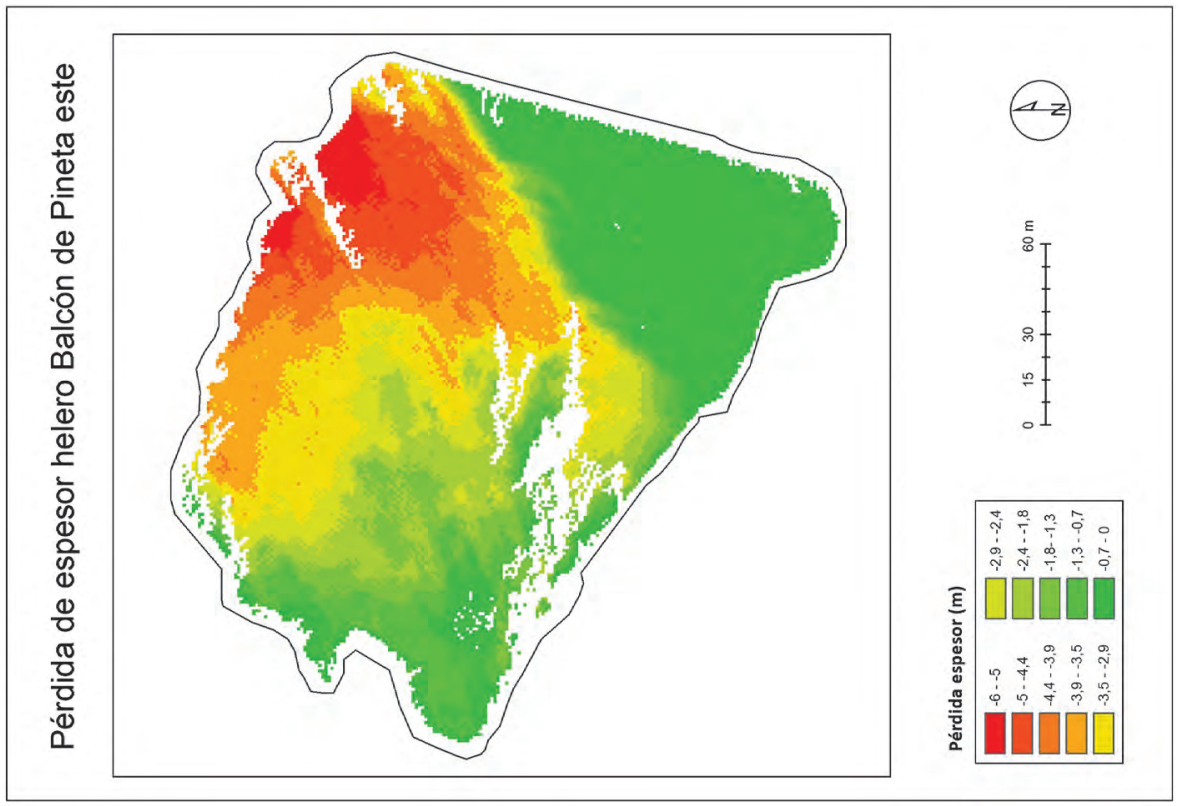

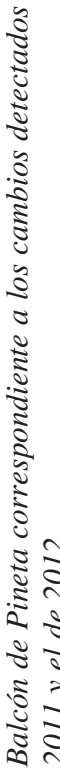
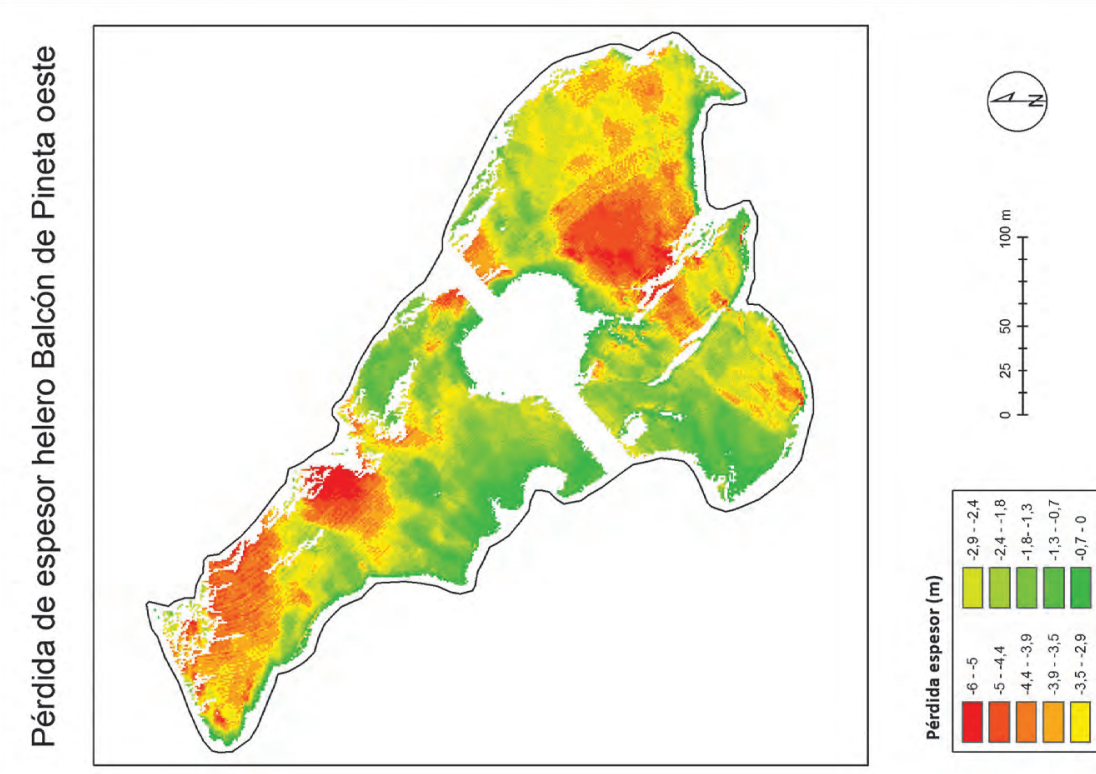


\section{Discusión y conclusiones}

Los ejemplos mostrados en el apartado anterior, son prueba de que la metodología descrita es aplicable en ambientes de alta montaña para la elaboración de un MDT de elevada resolución espacial. Sin embargo, la rápida evolución de esta tecnología en años recientes, hace que su aplicación todavía se considere novedosa y por ello hay que incidir en los problemas de su aplicación. Las limitaciones de la metodología vienen ligadas, en la mayoría de los casos, a problemas durante la adquisición de la información pues existen diversos factores que pueden influir negativamente en la calidad de los datos recogidos.

Si se comparan las desviaciones estándar en las coordenadas de los puntos de unión alcanzadas en este trabajo (entre $0.0084 \mathrm{~m}$ y $0.0247 \mathrm{~m}$ ), con las alcanzadas por otros autores de $0.002 \mathrm{~m}$ para reflectores (Prockop, 2008) puede parecer un error elevado. Sin embargo las distancias en las que se encontraban los puntos de unión son superiores (reflectores a menos de 450 m, frente a los 950 m entre algunos reflectores y el escáner en Izas) y originan mayores desviaciones, además de trabajar con otros modelos de TLS. Conviene destacar que los mayores errores obtenidos han coincidido con escaneos en los que no se pudo respetar el criterio de tiempo en el posicionamiento con los reflectores y la corrección atmosférica, o cuando las condiciones meteorológicas han sido adversas (viento intenso, precipitación en forma de lluvia o nieve, niebla, etc.). Los errores ligados a la adquisición de coordenadas globales de los reflectores con métodos GPS son inferiores al valor establecido como límite en el test de reproductibilidad señalado en el apartado 3.1.c (error de $20 \mathrm{~cm}$ a $600 \mathrm{~m}$ del escáner). Por ello la desviación en las coordenadas globales de los puntos de unión quedarían incluidos en los errores de la tecnología Láser Escáner.

Otra limitación de esta tecnología se deriva del traslado del sistema a las zonas de estudio. Transportar el equipo en alta montaña no resulta siempre sencillo; hay que reparar en el peso y el volumen del material transportado. El equipo completo de láser escáner, trípode, portátil y baterías pesa unos $45 \mathrm{~kg}$, además de tener unas dimensiones que hacen necesario un mínimo de dos personas para su transporte. Por ello las zonas de trabajo deben ser accesibles en distintas condiciones y para ello no pueden estar excesivamente distanciadas de un punto alcanzable en todoterreno. Sin embargo la principal ventaja del sistema es la adquisición de datos a larga distancia con una elevada resolución espacial, por lo que se dispone de millones de puntos distribuidos en prácticamente la totalidad de las zonas de estudio adquiridos desde tan solo dos posiciones de escaneo. Es precisamente esta característica la que hace que la tecnología láser escáner resulte ideal para trabajos de monitorización del manto de nieve para distancias de $500 \mathrm{~m}$ y superiores (Lundberg et al., 2008).

A la vista de los resultados expuestos, se dispone de mapas tanto de espesor de nieve como de pérdida de grosor en los heleros con una resolución espacial de un metro. Ello permite monitorizar la evolución del hielo y la nieve en las zonas de estudio. El nivel de detalle alcanzado con esta tecnología es superior al de otras técnicas, lo que posibilita aumentar los datos sometidos a estudio. Ejemplo de esta diferencia son los muestreos manuales realizados por López-Moreno y Latron (2008, 2010), que con un elevado coste de 
tiempo no proporcionan información tan exhaustiva. Los mapas de pérdida de espesor de hielo del balcón de Pineta confirman el proceso generalizado de retroceso glaciar de la actualidad (Chueca et al., 2005; Barnett et al., 2005). Estos resultados de balance de masa negativo muestran, al compararlos con Chueca et al. (2007), la tendencia generalizada de descenso en las masas de hielo en la alta montaña pirenaica en el periodo 1985-2005, acusándose más los cambios en los heleros y glaciares de menor tamaño.

Las campañas en las que se han recogido los datos analizados en el presente trabajo, tienen una duración temporal muy reducida por lo que no pueden deducirse implicaciones a medio o largo plazo en un escenario de cambio global. Por ello resulta muy importante continuar con estas mediciones que, mantenidas en el tiempo, proporcionarán una información muy valiosa de cara a comprender la respuesta del hielo y la nieve a la climatología local en zonas de alta montaña. Contextualizando la información que se está recogiendo en un proceso de cambio climático, con importantes implicaciones para la evolución del hielo de glaciares y heleros, así como en la duración de la cobertura de nieve en distintas áreas montañosas (Magnusson et al., 2010; López-Moreno et $a l ., 2009)$, se entiende la relevancia de aumentar el conocimiento de los procesos que gobiernan las citadas respuestas.

La información adquirida también resulta óptima para la validación de modelos hidrológicos, pues la nieve representa una de las variables con mayor incertidumbre por la, generalmente, escasa resolución espacial y temporal de los datos disponibles, habiéndose empleado para ello en algunos trabajos imágenes MODIS (Christensen et al., 2008). Por otro lado, procesos como la redistribución de la nieve por el viento no han podido ser correctamente parametrizados hasta el momento. Así, la respuesta de la nieve a los procesos de redistribución no viene implementada en la mayoría de los modelos hidrológicos, como RHESSys (Regional Hydro-Ecologic Simulation System) (Tague y Band, 2004), que a veces aumentan la incertidumbre de los resultados, como se ha comprobado con el CRHM (Cold Regions Hydrological Modelling) empleado en pequeñas cuencas del Pirineo (López-Moreno et al., en prensa). Los datos proporcionados por el TLS van a permitir aumentar el conocimiento de los procesos que controlan la variabilidad espacio-temporal del manto de nieve, además de aumentar los escasos datos disponibles en la actualidad de cobertura nivosa para la cordillera pirenaica.

Los resultados mostrados en este trabajo representan la primera aplicación en el Pirineo de un láser escáner terrestre de largo alcance de manera sistemática, aplicado a la monitorización del manto de nieve y hielo. Este trabajo ha pretendido mostrar el gran potencial de la metodología presentada para estudios en alta montaña. Por medio de la generación de MDTs de alta resolución obtenidos en distintos momentos, ya sea comparando la topografía en ausencia de nieve con las acumulaciones de nieve registradas, o bien los mapas obtenidos tras un año en el caso de los heleros, se obtienen los diferentes mapas de acumulación o de pérdida de espesor. Los errores en la adquisición de puntos se reducen drásticamente si se controla la estabilidad del escáner, la correcta georreferenciación de los reflectores, el registro de las nubes de puntos y eligiendo el momento de escaneo, evitando situaciones como viento intenso, precipitación o visibilidad limitada. Un correcto equilibrio entre distancia de escaneo y resolución de puntos 
de medición son necesarios para optimizar los tiempos de escaneo. La elevada velocidad en la adquisición de puntos así como la posibilidad de recoger datos desde un punto seguro, situado a grandes distancias de la zona de muestreo permiten asegurar que el TLS combinado con técnicas de georreferenciación por medio de GPS, representan una potente herramienta de trabajo. Se puede asegurar que siguiendo la metodología y respetando los límites señalados, los datos recogidos tendrán una calidad óptima para multitud de aplicaciones de estudios de la criosfera.

\section{Agradecimientos}

Este trabajo ha sido financiado por los proyectos CGL2011-27574-CO2-02 y CGL2011-27536, financiados por el Minsterio de Economía y Competitividad, ACQWA (FP7-ENV-2007-1- 212250), financiado por la Comisión Europea, el proyecto DGA-La Caixa: "Efecto de los escenarios de cambio sobre la hidrología superficial y la gestión de embalses del Pirineo Aragonés", y el proyecto financiado por la Comunidad de Trabajo de los Pirineos (CTTP01/12): "Creación de un modelo de alta resolución espacial para cuantificar la esquiabilidad y la afluencia turística en el Pirineo bajo distintos escenarios de cambio climático".

\section{Referencias bibliográficas}

Abellán, A., Vilaplana, J.M., Martínez, J. 2006. Application of a long-range Terrestrial Laser Scanner to a detailed rockfall study at Vall de Núria (Eastern Pyrenees, Spain). Engineering Geology 88, 136-148.

Abellán, A., Calvet, J., Vilaplana, J.M., Blanchard, J. 2010. Detection and spatial prediction of rockfalls by means of terrestrial laser scanner monitoring. Geomorphology 119, 162-171.

Andersen T., Lundteigen-Fossdal, M., Killingtveit, A., Sand, K. 1987. The snow radar: A new device for areal snow depth measurements. "Hydropower 87" International Conference, Norwegian Hydrotechnical Laboratory Bulletins, Norway, pp. 269-274.

Anderton, S.P., White, S.M., Alvera, B. 2004. Evaluation of spatial variability in snow water equivalent for a high mountain catchment. Hydrological Processes 18, 435-453.

Avian, A., Bauer, A. 2006. First Result on Monitoring Glacier Dynamics with the Aid of Terrestrial Laser Scanning on Pasterze Glacier (Hoe Tauren, Austria). 8th International Symposium on High Mountain Remote Sensing Cartography, Band 41/2006, pp. 27-36.

Barnett, T.P., Adam, J.C., Lettenmaier, D.P. 2005. Potential impacts of a warming climate on water availability in snow-dominated regions. Nature 438, 303-309.

Beniston, M. 2003. Climate change in mountain regions: A review of possible impacts. Climatic Change 59, 5-31.

Bitelli, G., Dubbini, M., Zanutta, A. 2004. Terrestrial Laser Scanning and Digital Photogrammetry Techniques to Monitor Landslides Bodies, ISPRS 2004 International Society for Photogrammetry and Remote Sensing Comission V, WG V/2.

Bürki, R., Elsässer, B., Abegg, B. 2003. Climate change: Impacts on the Tourism Industry in Mountain Areas. Proceedings, 1st International Conference on Climate Change and Tourism, Djerba, Tunisia, pp. 1-8.

Cano, I.C., Recio, J.A. 2004. Análisis comparativo de distintos métodos de estimación de la superficie glaciar en el Pirineo axial aragonés a partir de imágenes Landsat. GeoFocus 4, 79-92. 
Chueca, J., Julián-Andrés, A., Saz-Sánchez, M.A., Creus-Novau, J., López-Moreno, J.I., 2005. Responses to climatic changes since the Little Ice Age on Maladeta Glacier (Central Spanish Pyrenees). Geomorphology 68, 167-182.

Chueca, J., Julián-Andrés, A., López-Moreno, J.I. 2007. Recent evolution (1981-2005) of the Maladeta glaciers, Pyrenees, Spain: extent and volume losses and their relation with climatic and topographic factors. Journal of Glaciology 53, 247-257.

Christensen, L., Tague, C.L., Baron, J.S. 2008. Spatial patterns of simulated transpiration response to climate variability in a snow dominated mountain ecosystem. Hydrological Processes 22 , 3576-3588.

Deems, J.S., Fassnacht, S.R., Elder, K.J. 2006. Fractal Distribution of snow depth from Lidar data. American Meteorological Society 7, 285-297.

Del Río, M., Rico, I., Serrano, E., Tejado, J.I. 2012. GPR Prospection in the Ossoue Glacier (Pyrenees). 14th International Conference on Ground Penetrating Radar (GPR), Shanghai, China.

Egli, L., Jonas, T., Grünewald, T., Schirmer, M., Burlando, P. 2012. Dynamics of snow ablation in a small Alpine catchment by repeated terrestrial laser scans. Hydrological Processes 26, 1574-1585.

Erxleben, J., Elder, K., Davis, R. 2002. Comparison of spatial interpolation methods for estimating snow distribution in the Colorado Rocky Mountains. Hydrological Processes 16, 3627-3649.

Fassnacht, S.R. 2010. Temporal changes in small scale snowpack surface roughness length for sublimation estimates in hydrological modelling. Cuadernos de Investigación Geográfica 36 (1), 43-57.

Grünewald, T., Schirmer, M., Mott, R., Lehning, M. 2010. Spatial and temporal variability of snow depth and ablation rates in a small mountain cathment. The Cryosphere 4, 215-225.

Guneriussen, T., Hogda, K.A., Johnsen, H., Lauknes, I. 2001. InSAR for estimation of changes in snow water equivalent of dry snow. IEEE Transactions on Geoscience and Remote Sensing 39, 2101-2108.

Haeberli, W., Beniston, M. 1998. Climate change and its impacts on glaciers and permafrost in the Alps. Research for Mountain Area Development: Europe 27, 258-265.

Hall, D.K., Riggs, G.A., Salomonson, V. 1995. Development of Methods for Mapping Snow Cover Using Moderate Resolution Imaging Spectroradiometar Data. Remote Sensing and Environment 54, 127-140.

Heritage, G., Hetherington, D. 2007. Towards a protocol for laser scanning in fluvial geomorphology. Earth Surface Processes and Landforms 32, 66-74.

Ingensand, H. 2006. Metrological aspects in terrestrial laser-scanning technology. $3^{\text {rd }} I A G / 12^{\text {th }}$ FIG Symposium, Baden.

Jaboyedof, J., Oppikofer, T., Abellán, A., Derron, M.H., Loye, A., Metzger, R., Pedrazzini, A. 2012. Use of LIDAR in landslide investigations: a review. Natural Hazards 61, 5-28.

König, M., Winther, J.G. 2001. Measuring snow and glacier ice properties from satellite. Review of Geophysics 39, 1-27.

Lana-Renault, N., Alvera, B., García-Ruiz, J.M. 2010. The snowmelt period in a Mediterranean high mountain catchment: runoff and sediment transport. Cuadernos de Investigación Geográfica 36 (2), 97-106.

Lana-Renault, N., Alvera, B., García-Ruiz, J.M. 2011. Runoff and sediment transport during the snowmelt period in a Mediterranean high mountain catchment. Arctic, Antarctic and Alpine Research 42 (2), 213-222.

Lichte, D., Jamtsho, S. 2006. Angular resolution of terrestrial laser scanners. The Photogrammetric Record 21, 141-160. 
López-Moreno, J.I., García-Ruiz, J.M. 2004. Influence of snow accumulation and snowmelt on stream flow in the central Spanish Pyrenees. Hydrological Sciences Journal des Sciences 49, 787-802.

López-Moreno, J.I., Nogués-Bravo, D. 2006. Interpolating local snow depth data: an evaluation of methods. Hydrological Processes 20, 2217-2232.

López-Moreno, J.I., Vicente-Serrano, S.M. 2007. Atmospheric influence on the interannual variability of snow pack in the Spanish Pyrenees during the second half of the 20th century. Nordic Hydrology 38, 33-44.

López-Moreno, J.I., Latron, J. 2008. Influence of canopy density on snow distribution in a temperate mountain range. Hydrological Processes 22, 117-126.

López-Moreno, J.I., Nogués-Bravo, D., Chueca, J., Julián-Andrés, A. 2006. Change of topographic control on the extent of cirque glaciers since the Little Ice Age. Geophysical Research Letters 33, L24505.

López-Moreno, J.I., Vicente-Serrano, S.M., Lanjeri, S. 2007. Mapping snowpack distribution over large areas using GIS and interpolation techniques. Climate Research 33, 257-270.

Lopez-Moreno, J.I., Beniston, M., García-Ruiz, J.M. 2008. Environmental change and water management in the Pyrenees: Facts and future perspectives for Mediterranean mountains. Global and Planetary Change 61, 300-312.

López-Moreno, J.I., Goyette, S., Beniston, M. 2009. Impact of climate change on snowpack in the Pyrenees: Horizontal spatial variability and vertical gradients. Journal of Hydrology 374, 384-396.

López-Moreno, J.I., Latron, J., Lehmann A. 2010. Effects of simple and grid size on the accuracy and stability of regression- based snow interpolation methods. Hydrological Processes 24, 1914-1928.

López-Moreno, J.I., Pomeroy, J., Revuelto, J., Vicente-Serrano, S.M. En prensa. Response of snow processes to climate change: spatial variability in a small basin in the Pyrenees. Hydrological Processes. DOI: 10.1002/hyp.9408.

Lundberg, A., Granlund, N., Gustafsson, D. 2008. "Ground truth" snow measurements: review of operational and new measurements methods for Sweden, Norway and Finland. Hydrological Processes 24, 1955-1970.

Magnusson, J., Tobias, J., López-Moreno, J.I., Lehning, M. 2010. Snow cover response to climate change in a high alpine and half basin in Switzerland. Hydrology Research 41, 230-240.

Molotch, N.P., Colee, M.T., Bales, R.C., Dozier, J. 2005. Estimating the spatial distribution of snow water equivalent in an alpine basin using binary regression tree models: the impact of digital elevation data and independent variable selection. Hydrological Processes 19, 1459-1479.

Oppikofer, T., Jaboyedoff, M., Keusen, H.R. 2008. Collapse at the eastern Eiger flank in the Swiss Alps. Nature Geoscience 1, 531-535.

Parajka, J., Blöschl, G. 2008. Spatio-temporal combination of MODIS images- potential for snow cover mapping. Water Resources Research 44, W03406.

Pomeroy, J., Essery, R., Toth, B. 2004. Implications of spatial distribution of snow mass and melt rate for snow-cover depletion: observations in a subarctic mountain catchment. Annals of Glaciology 38, 195-201.

Prockop, A. 2008. Assessing the applicability of terrestrial laser scanning for spatial snow depth measurements. Cold Regions Science and Technology 54, 155-163.

Prockop, A. 2009. Terrestrial laser scanning for snow depth observations: An update on technical developments and applications. International Snow Science Workshop, Proceedings, Davos, pp. 192-196. 
Prockop, A., Schirmer, M., Rub, M.,Lehning, M., Stocker, M. 2008. A comparison of measurements methods: terrestrial laser scanning, tachymetry and snow probing for the determination of the spatial snow depth distribution on slopes. Annals of Glaciology 49, 210-216.

Reshetyuk, J. 2006. Investigation and calibration of pulsed time-of-flight terrestrial laser scanners. Tesis Doctoral. Royal Institute of Technology (KTH), Department of Transport and Economics, Division of Geodesy, Stockholm.

Romanescu, G., Cotiuga, V., Asandulesei, A., Stoleriu, C. 2012. Use of 3-D scanner in mapping and monitoring the dynamic degradation of soils: case study of the Cucuteni-Baiceni Gully on the Moldavian Plateau (Romania). Hydrology and Earth System Sciences 16, 953-966.

Rosenthal, W., Dozzier, J. 1996. Automated mapping of montane snow cover at subpixel resolution from the Landsat Thematic Mapper. Water Resources Research 32, 115-130.

Rott, H., Nagler, T., Scheiber, R. 2004. Snow mass retrieval by means of SAR interferometry. Proceedings of FRINGE 2003 Workshop, ESA SP-550, Frascati, 6 pp.

Scaioni, M. 2005. Direct georreferencing of TLS in surveying of complex sites. Proceedings of the ISPRS Working Group. International Society of Photogrammetry and Remote Sensing $36,1-8$.

Schaffhauser, A., Adams, M., Fromm, R., Jorg, P., Luzi, G., Noferini, L., Sailer, R., 2008. Remote sensing based retrieval of snow cover properties. Cold Regions Science and Technology 54, 164-175.

Schwalbe, E., Maas, H.G., Dietrich, R., Ewert, H. 2008. Glacier Velocity determination from multitemporal terrestrial long range laser scanner point clouds. The International Archives of the Photogrammetry, Remote Sensensing and Spatial Information Sciences 37, 457-462.

Singh, P., Singh, V.P. 2001. Snow and glacier hydrology. Kluwer Academic Publishers, Dordrecht, $756 \mathrm{pp}$.

Tague, C.L., Band, L.E. 2004. RHESSys: Regional Hydro-Ecologic Simulation System-An object orientated approach to spatially distributed Modeling of Carbon, Water and Nutrient Cyling. Earth Interactions 8, 1-42.

Wagner, W., Ullrich, A., Melzer, T., Breise, C., Kraus, K. 2004. From single-pulse to full waveform airborne laser scanners: potential and practical challenges. International Archives of Photogrammetry and Remote Sensing and Geoinformation Sciences 35, 414-419.

Wehr, A., Lohr, U. 1999. Airbone laser scanning: an introduction and overview. ISPRS Journal of Photogrammetry \& Remote Sensing 54, 68-82. 